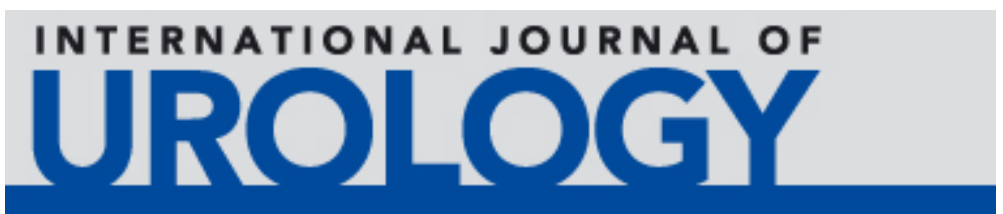

\title{
Cadaveric Penile Prosthesis Workshop training improves surgical confidence levels of Urologists: South Asian Society of Sexual Medicine Course Survey
}

\begin{tabular}{|c|c|}
\hline Journal: & International Journal of Urology \\
\hline Manuscript ID & IJU-00236-2020.R1 \\
\hline Manuscript Type: & Original Article \\
\hline $\begin{array}{r}\text { Date Submitted by the } \\
\text { Author: }\end{array}$ & $\mathrm{n} / \mathrm{a}$ \\
\hline Complete List of Authors: & $\begin{array}{l}\text { Krishnappa, Pramod; NU Hospitals, Urology } \\
\text { Srini, Vasan; Ankur Healthcare, Andrology } \\
\text { Shah, Rupin; Lilavati Hospital and Research Centre, Andrology } \\
\text { Lentz, Aaron; Duke University, Urology } \\
\text { Garaffa, Giulio; University College London Hospitals NHS Foundation } \\
\text { Trust, Urology } \\
\text { Martinez-Salamanca, Juan; Hospital Universitario Puerta del Hierro } \\
\text { Majadahonda, Urology } \\
\text { Moncada, Ignacio; Hospital Universitario La Zarzuela, Department of } \\
\text { Urology }\end{array}$ \\
\hline Key Words: & Erectile Dysfunction, Penile Prosthesis, Cadaver, Andrology, Asia \\
\hline Abstract: & $\begin{array}{l}\text { Objectives: Andrology subspecialty is still evolving in South Asian } \\
\text { Countries. Due to easy internet access these days, the increased } \\
\text { awareness among the general public about penile prosthesis as an option } \\
\text { for Erectile dysfunction has intrigued many urologists to seek training in } \\
\text { Penile Prosthesis surgery. The aim was to analyse the outcomes of South } \\
\text { Asia's first cadaveric Penile Prosthesis hands-on workshop on the } \\
\text { urologists. } \\
\text { Methods: } 72 \text { urologists/ andrologists participated in } 2019 \text { South Asian } \\
\text { Society of Sexual Medicine Pre-congress Penile Prosthesis hands-on } \\
\text { workshop. The workshop included } 4 \text { hours of lectures and } 2 \text { hours of } \\
\text { hands-on cadaveric lab experience using three-piece inflatable Penile } \\
\text { Prosthesis. Shapiro Wilk test was used on self rated procedural } \\
\text { confidence levels which proved the normality. Non-parametric McNemar } \\
\text { test was used to look at the change in number of correct answers. } \\
\text { Results: Of the } 72 \text { who attended the cadaver lab, only } 45 \text { who answered } \\
\text { the survey both before and after the workshop were included for } \\
\text { analysis. Significant objective improvements were noted after the } \\
\text { completion of the workshop in procedural knowledge test scores (44.30 } \\
+0.027 \text { vs } 72.44+0.024, \text { p }<0.05 \text { ) and median surgical confidence } \\
\text { levels ( } 4 \text { vs } 3, \text { and } 2, \text { p<0.001) of the urologists. } \\
\text { Conclusion: Cadaveric hands-on workshop training improves procedural } \\
\text { knowledge and surgical confidence levels of urologists in performing } 3- \\
\text { piece inflatable Penile Prosthesis surgery. The feasibility of such } \\
\text { workshops should be considered in increasing the surgical expertise of } \\
\text { general urologists in prosthetic urology. }\end{array}$ \\
\hline
\end{tabular}


SCHOLARONE $^{\text {TM }}$
Manuscripts

Manuscripts 


\section{$\underline{\text { Title page }}$}

\section{Cadaveric Penile Prosthesis Workshop training improves surgical confidence levels of Urologists: South Asian Society of Sexual Medicine Course Survey}

Pramod Krishnappa ${ }^{1}$, Vasan S Srini ${ }^{2}$, Rupin Shah ${ }^{3}$, Aaron C Lentz ${ }^{4}$, Giulio Garaffa ${ }^{5}$, Juan

Ignacio Martinez-Salamanca ${ }^{6}$, Ignacio Moncada ${ }^{7}$

1 Andrology Division, Dept of Urology, NU Hospitals, Bangalore, India

2 Dept of Andrology, Ankur Healthcare, Bangalore, India

3 Dept of Andrology, Lilavati Hospital, Mumbai, India

4 Dept of Urologic Surgery, Duke University, Raleigh, NC, USA

5 Dept of Urology, University College of London Hospital (UCLH), London, UK

6 Dept of Urology, Hospital Universitario Puerta de Hierro, Madrid, Spain

7 Dept of Urology \& Robotic Surgery, Hospital Universitario La Zarzuela, Madrid, Spain

Short title: Penile Implant Cadaveric Workshop

Corresponding author:

Dr Pramod Krishnappa, Head of Andrology division, Dept of Urology, NU Hospitals, Rajajinagar, Bangalore - 560010, India. Pramod23dr@gmail.com Ph:(+91)080-42489999.

\section{Word count:}

Abstract 232

Manuscript 2573

\section{AUTHORSHIP:}

All authors have:

1) Substantial contributions to the conception or design of the work, or acquisition, analysis or interpretation of data for the work;

2) Drafted the work and revised it critically for important intellectual content;

3) Final approval of the version to be published;

4) Agreed to be accountable for all aspects of the work in ensuring that questions related to the accuracy or integrity of any part of the work are appropriately investigated and resolved. 


\section{ABSTRACT}

Objectives: Andrology subspecialty is still evolving in South Asian Countries. Due to easy internet access these days, the increased awareness among the general public about penile prosthesis as an option for Erectile dysfunction has intrigued many urologists to seek training in Penile Prosthesis surgery. The aim was to analyse the outcomes of South Asia's first cadaveric Penile Prosthesis hands-on workshop on the urologists.

Methods: 72 urologists/ andrologists participated in 2019 South Asian Society of Sexual Medicine Pre-congress Penile Prosthesis hands-on workshop. The workshop included 4 hours of lectures and 2 hours of hands-on cadaveric lab experience using three-piece inflatable Penile Prosthesis. Shapiro Wilk test was used on self rated procedural confidence levels which proved the normality. Non-parametric McNemar test was used to look at the change in number of correct answers.

Results: Of the 72 who attended the cadaver lab, only 45 who answered the survey both before and after the workshop were included for analysis. Significant objective improvements were noted after the completion of the workshop in procedural knowledge test scores $(44.30 \pm 0.027$ vs $72.44 \pm 0.024, p<0.05)$ and median surgical confidence levels $(4$ vs 3 , and $2, p<0.001$ ) of the urologists.

Conclusion: Cadaveric hands-on workshop training improves procedural knowledge and surgical confidence levels of urologists in performing 3-piece inflatable Penile Prosthesis surgery. The feasibility of such workshops should be considered in increasing the surgical expertise of general urologists in prosthetic urology.

\section{KEYWORDS:}

Erectile Dysfunction, Penile Prosthesis, Cadaver, Andrology, Asia, Training, learning curve, Surgery

\section{ABBREVIATIONS:}

PP: Penile Prosthesis

SASSM: South Asian Society of Sexual Medicine 
AMS: American Medical Systems Inc

ED: Erectile Dysfunction

ESSM: European Society of Sexual Medicine

ISSM: International Society of Sexual Medicine

\section{INTRODUCTION:}

There has been a lack of adequate surgical training exposure during the urology residency due to various factors such as increased number of residents in a particular residency program, restrictions on working hours of residents, legal issues and long waiting lists. ${ }^{1-3}$

The urology training period varies from country to country. The shortest possible time to board certification in urology is 2 years in the Ukraine and longest is 9 years in the United Kingdom. ${ }^{4}$

The American urology residency programs last for 5 or 6 years depending on the institute. ${ }^{5}$ The urological training in India is a three-year program after having compulsorily completed three years in general surgery. ${ }^{6}$

It is practically impossible to get trained in all subspecialties of Urology (Endourology, Reconstructive Urology, Andrology, Paediatric urology, Uro-oncology, Uro-gynecology) during urology residency and most urology residents tend to acquire skills in endourology only. Andrology is still in its infancy in most urology residency programs.

The most sought out urology residency programs are in USA and $63.8 \%$ of the institutions in USA have no faculty member dedicated to andrology/male infertility care. ${ }^{7}$

Hence there is a need to train urologists using simulation based training to fill in the lacunae of urology training. ${ }^{8}$ 
Renterghem rightly pointed out that the traditional Halsted principle of "see one, do one, teach one" is no more feasible given the recent financial, medico-legal, and ethical considerations of intraoperative training. ${ }^{9}$

Various options in simulation training include animal models (like pig), synthetic models, cadaveric labs and virtual reality models.

A cadaveric skills course is an effective training model to improve the clinical operative experience and to get initial exposure to fundamental techniques of a specific surgery. ${ }^{10-11}$ Although the porcine models are better for tissue handling and to dissect tissue planes, cadavers are more anatomically relevant. ${ }^{12}$

In Andrology, no animal model is good enough to learn PP surgery.

Barriers to execute simulation based training include regular updates in technology, cost, need for advance planning to get the consumables and difficult to spare time in hectic residency hours in high-volume centres. ${ }^{13}$

Lentz AC et al first documented the positive outcomes of training American residents in PP surgery using cadaveric models as part of the 2017 Society of Urologic Prosthetic Surgeons and Sexual Medicine Society of North America Annual Meeting. The group noted significant improvement in procedural test scores and median surgical confidence levels. ${ }^{14}$

The purpose of this study was to analyse the impact of the cadaver lab course on urologists and andrologists predominantly of South Asian countries in learning the 3-piece inflatable PP surgery.

\section{METHODS:}

SASSM had its $4^{\text {th }}$ biennial congress on 22-24 th November 2019 in Bangalore, India. As a part of the pre-congress event, the PP workshop was organised on $21^{\text {st }}$ Nov 2019 which was first of its kind in South Asia.

In order to provide opportunity for sexual medicine care givers to understand about PP, the option of "observers" was open for non-urologists and the hands-on participation was strictly restricted to Urologists / Andrologists. 
The workshop included 10 observers (non-urologists) and 72 hands-on participants (urologists/ andrologists) from India, Bangladesh, Srilanka and Egypt. The morning session included 4 hours of interactive practical oriented lectures about PP. The afternoon session included 2 hours of hands-on experience for urologists in cadaver lab and simultaneous video relay of hands-on procedure of one cadaver station to "observers" in the lecture hall. One minute silence was observed before entering the cadaver lab and prayers were offered to the departed souls who voluntarily had donated their bodies for research activities.

There were a total of 12 cadaveric stations ( 1 fresh and 11 thiel embalmed cadavers). Each cadaveric station had 1 cadaver, 1 tutor and 6 hands-on participants (Fig 1). Only the Penoscrotal approach for PP surgery was uniformly followed at all cadaveric stations.

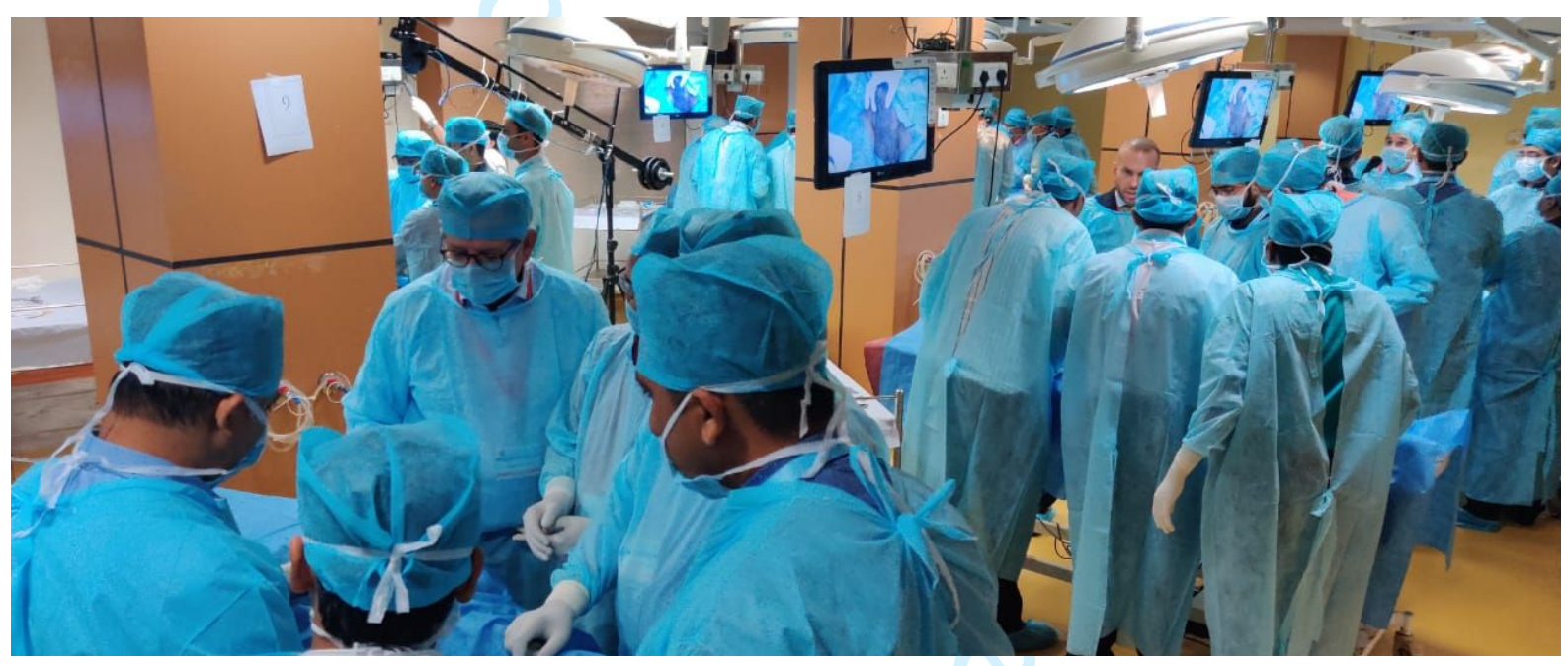

\section{Fig 1: Cadaver stations}

As there are many surgical steps in 3-piece inflatable PP AMS 700 placement, distribution of hands-on opportunities among the 6 participants was distributed at each cadaver station as below:

Role of participant 1\&2:

a. Foley catheter insertion

b. Placement of Ring retractor and Penoscrotal skin incision

c. Dissection of dartos and reaching the corpora cavernosa on either sides

d. Stay sutures on one (right) corpora 


\section{e. Corporotomy}

f. Dilatation of corpora

g. Insertion of Furlow and measurement of corporal (proximal and distal) length

h. Deciding the size of implant

i. Keith needle and Furlow preparation

j. Placement of cylinder

Role of participant $3 \& 4$ :

Repeat steps on other (left) corpora from step " $d$ " to "j" and place the pump in scrotum. Role of Participant 5:

Reservoir insertion in space of retzius on one (right) side.

Role of Participant 6:

Remove the same reservoir and put in on other (left) side. Then make the final connections.

Entire implant could be removed and the whole procedure could be repeated individually by each participant to get a hang of most vital steps such as knowing the proximal-distal corporal extents, usage of Keith needle, Furlow, pump placement, reservoir position etc.

\section{Financial details of organising this workshop to help future organisers in Asia:}

The registration fee for hands-on participant was INR 20000 -25000 (USD 280-350) and observer fee was INR 8000-10000 (USD 110-140) depending on early and late registration through SASSM website. Accommodation and travel expenses were separately borne by the participants themselves. No monetary support was given by any company to organise the event. Boston Scientific and Hospimedica provided the 3-piece inflatable PP and the supporting instruments needed for the workshop. Each cadaver station costed approximately 39,000 INR (545 USD), which included the cost of the cadaver, cadaver lab space, basic surgical instruments, technician costs and disposables like gown, mask. Cadavers were voluntary donated for research activity. 
The national faculty were not offered any financial assistance and they came on their own (including flight and stay), as they attended the SASSM congress as well.

All 72 hands-on participants were sent a link on email two weeks prior to the start of the workshop to complete the pre-workshop survey. The same link was re-sent through email after the workshop and was valid till next one week for them to complete the postworkshop survey.

The survey was a form based branched questionnaire conducted via Microsoft Forms with the support of Lupin India. Microsoft forms allow educators to create surveys and quizzes with automatic marking. The data was exported to Microsoft Excel for statistical analysis.

The survey had two sections: first section contained 15 questions which assessed the handson participant's knowledge on PP surgery and the second section contained 15 questions which involved self rated surgical confidence levels in placing a 3-piece PP. 5-point Likert scale was used to quantify the surgical confidence level (Not at all confident, minimally confident, average confidence, above average confidence, very confident). This survey questionnaire was adapted from the previous study by Lentz AC et al. ${ }^{14}$

The 10 "observers" were not included in the study. Of the 72 "hands-on" participants, only 45 completed both pre and post-workshop survey. Hence only 45 were considered for analysis. Those who answered only a pre-workshop or post-workshop survey alone were excluded.

\section{Statistical analysis:}

The procedural knowledge test score was obtained by adding all the correct responses and dividing by total number of questions. Non-parametric McNemar test was used to look at the change in number of correct answers. Shapiro Wilk test was used on self-rated procedural confidence which proved the Normality. To check if the confidence has increased, pair $T$ test was used. $P$ value of 0.05 was considered statistically significant.

\section{RESULTS:}

All 45 participants who completed both pre and post-workshop questionnaires had already completed their residency training and were consultant urologists/andrologists. Table 1 summarises their characteristics. 
Majority (71.1\%) of the participants had no prior experience with PP.

\section{a. Analysis of first section of the survey: 15 Questions related to procedural knowledge about PP surgery.}

Significant improvement was noted in procedural knowledge test scores $(44.30 \pm 0.027$ vs $72.44 \pm 0.024, p<0.05$ ) after the workshop (Fig 2a).

Table 2 highlights the change in correct answers in pre and post-workshop survey. For example: 28/45 (62\%) had got correct answers for question 1 in pre-workshop survey, which improved to $37 / 45$ (82.2\%) getting correct answers for the same question in post-workshop survey.

Out of the 15 questions, significant improvement in correct answers was observed in all questions except question numbers 9, 11, 12 and 13 after the workshop (total number of correct answers pre-workshop = 299; total number of correct answers after workshop = 489, Significant difference: $p<.0001)$

The question 9 was about the additional feature of AMS 700 LGX when compared to CX. The participants may be didn't agree with the additional length expansion with LGX as claimed by Boston Scientific. The question 11 was about urethral injury during corporal dilatation. Although many agreed that the PP surgery should be aborted when there is a urethral injury during corporal dilatation, some urologists chose to leave suprapubic catheter instead of urethral catheter. Question 12 dealt with post-implant infection where scrotal pain and adherence of scrotal skin to pump is usually due to gram positive organisms, but few still opted for gram negative organisms as the cause. The participants probably opted for gram negative organisms similar to urinary tract infection microbial flora which the general urologists most commonly deal with in their day-to-day clinical practice. Cylinder crossover was addressed in question 13 and number of correct answers almost remained the same (32 to 33 ) with no significant improvement.

The maximum improvement (correct answers from 6 to 43) was seen with question 5 which highlighted the fact that smoking has higher risk of implant infection.

\section{b. Analysis of second section of the survey: 15 questions related to self rated} procedural confidence levels based on Likert scale. 
As evident in table $\mathbf{3}$ and Fig $\mathbf{2 b}$, the level of procedural confidence significantly $(p<.001)$ improved after the workshop in all the 15 questions.

The table 4 shows the median confidence per statement, in the pre and post workshop survey. The median confidence level was significantly higher in the post workshop survey (4 vs 3 , and $2, P<.001)$. There was a significant difference in confidence between pre and post workshop in all questions analyzed separately (all medians increased, all $\mathrm{P}<.001$ ).

Fig 2a: Percentage difference in test scores from pre and post assessment [ $Y$ axis is percentage; $X$ axis is question number]

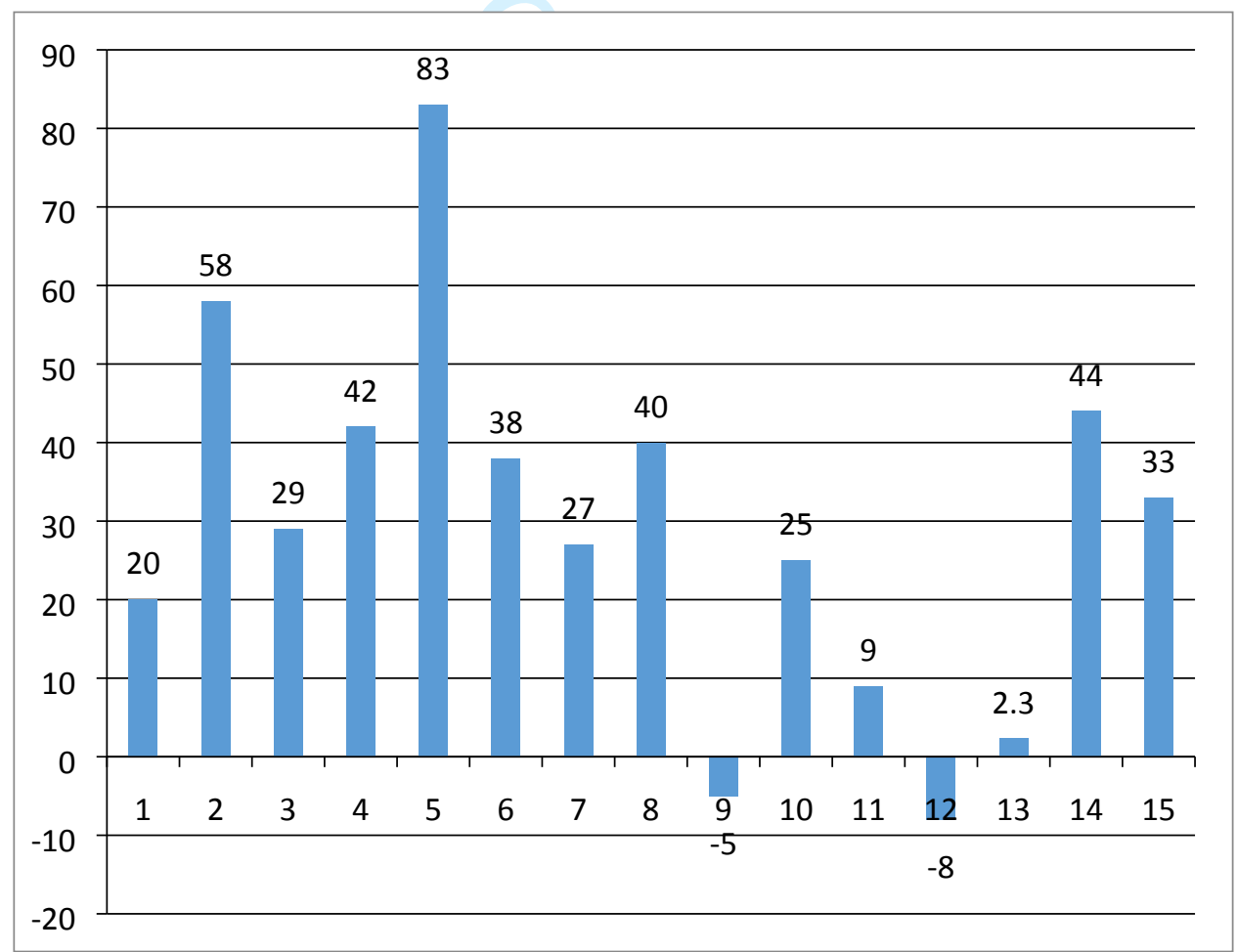

Fig $2 \mathrm{~b}$ : Difference in median confidence pre and post workshop ( $X$ axis- Question number, $Y$ axis- score range from 1 to 5 ) 


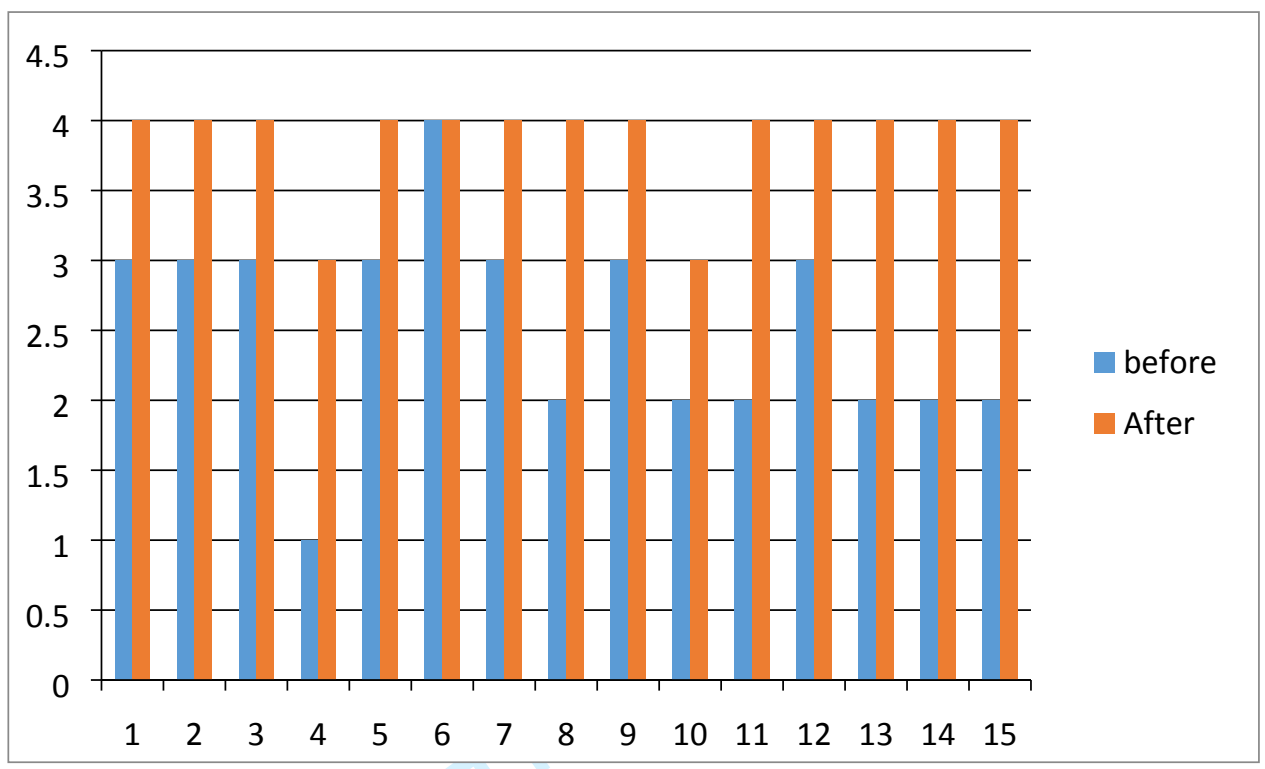

Subgroup analysis based on implant experience was not done as majority (71.1\%) of the participants had no prior implant experience.

\section{DISCUSSION:}

Due to the widespread availability of affordable internet, it has become easy for ED patients to access all possible treatment modalities for ED. Phosphodiesterase- 5 inhibitors advertisements are now common and people are more open to discuss about various options for ED including PP. ${ }^{15}$

Majority of the centres even in developed countries do not have expertise in PP surgery. Only $15 \%$ of urology training programs in USA have a dedicated prosthetic urologist. ${ }^{16}$ The major concerns for general urologists to start PP surgery is lack of training, higher costs of the PP and misinformation about higher complication rates and poor outcomes. ${ }^{17}$

Hence simulation training programs are need of the hour and Lentz AC et al first published the positive outcomes of simulation surgical training for urology residents in PP surgery. The results of our study reiterate the fact that the cadaveric training in PP improves procedural knowledge test scores and surgical confidence levels similar to the study published by Lentz $\mathrm{AC}$ et al. ${ }^{14}$ 
Our study had no urology residents; instead all were consultant urologists / andrologists. The major challenge that was encountered in the cadaver lab was that the tissue planes of some cadavers which were thiel embalmed were not good for dissection and hence significant effort had to be put for corporal dilatation. Our suggestion henceforth is to have fresh cadavers as much as possible for the workshops so that participants can have a real life experience of tissue planes. But availability of so many fresh cadavers on a single day is again a concern.

There was decrease in the number of correct answers for question 9 which quizzed about the added advantage of LGX PP. Boston Scientific claims that the LGX has an added advantage of length expansion but the study from Wallen JJ et al rebutted this length expansion claim in their study published in 2019. An increase in stretched penile length was seen in only 6 (23.1\%) patients in whom they had used LGX PP. ${ }^{18}$

Lentz AC et al study opined about giving longer window period to complete the postworkshop survey. Hence having given two weeks time before the start of the workshop and upto one week after the workshop was considered adequate for the participants to complete the survey in our study. ${ }^{14}$

The common concerns raised by the participants in the cadaver lab were the placement of reservoir and high cost of the 3-piece penile PP for South Asian scenario. The high volume prosthetic urologists prefer to place the reservoir through the same penoscrotal incision. To understand the anatomical landmarks better and to appreciate the plane of placing the reservoir, counter-incisions were placed in suprapubic region to demonstrate the placement of reservoir in space of retzius. The cost of 3-piece PP is very expensive considering the average income of South Asian population; hence a 2-piece inflatable or malleable PP would be more acceptable option for South Asian patients.

The highlight of this study was that this was the first cadaveric workshop for PP in South Asia organised by SASSM having involved mentors from premier sexual medicine societies namely ESSM and ISSM in the only available cadaveric academic training lab in India. 
Limitations of this study include the usage of non-validated questionnaire. Although using a questionnaire is the simplest way to avoid bias but it is obviously still far from the reality of the operating theatre. It is difficult to evaluate if the skills acquired in the cadaver lab will really translate to better results and increased confidence levels while operating on live patients.

Our future plans would be evaluating not only knowledge and confidence, but outcomes from future procedures in the hospital. This may be somewhat difficult because the field of andrology and prosthetic urology is still growing in Asia. Perhaps adding live surgery to the cadaveric workshop would be the second step and the mentoring of the trainees in their centres helping them in the first cases would be the end of the training process.

Due to inadequate surgical opportunities during residency and lack of andrology fellowship programs in South Asian countries, cadaveric hands-on workshop in PP surgery is an innovative practical solution to improve procedural knowledge and surgical confidence level of urologists to perform 3-piece inflatable PP surgery. The advantages and disadvantages of such simulation training program need further validation and research.

\section{ACKNOWLEDGEMENT:}

We thank Mr Akshay Rane and Lupin India for helping us prepare the survey questionnaire free of cost. We are thankful to Boston Scientific India (Bhavna Sapra, Kanika Suri, and Sanjay Sharma) and Hospimedica team (Sanjay Das and Kundan Singh Thakur) for providing us the penile implants, necessary surgical instruments and assisting the trainees during the workshop. We are also grateful to the team of NU Hospitals Bangalore for hosting the theory session and taking care of logistics and food. Special thanks to the team at Ramaiah Advanced Learning Centre for the smooth coordination in the cadaveric lab.

\section{CONFLICT OF INTEREST: None}

\section{REFERENCES:}

1. Cocci A, Patruno G, Gandaglia G, Rizzo M, Esperto F et al. Urology Residency Training in Italy: Results of the First National Survey. Eur Urol Focus 2018 Mar;4(2):280-287.

2. Borgmann H, Arnold HK, Meyer CP, Bründl J, König J, Nestler T et al. Training, Research, and Working Conditions for Urology Residents in Germany: A Contemporary Survey. Eur Urol Focus 2018 Apr;4(3):455-460. 
3. Carrion DM, Rodriguez-Socarrás ME, Mantica G, Esperto F, Cebulla A, Duijvesz D et al. Current status of urology surgical training in Europe: an ESRU-ESU-ESUT collaborative study. World J Urol 2020 Jan;38(1):239-246.

4. Parkar SP, Fuglsig S, Nunes P, Keskin S, Kniestedt WJ, Sedelaar JP, et al. Urological training in Europe: Similarities and differences. BJU Int. 2005;96:207-11.

5. Okhunov Z, Safiullah S, Patel R, Juncal S, Garland H, Khajeh NR et al. Evaluation of Urology Residency Training and Perceived Resident Abilities in the United States. J Surg Educ 2019 Jul - Aug;76(4):936-948.

6. Monish Aron. Urology training in India: Balancing national needs with global perspectives. Indian J Urol 2009 Apr-Jun; 25(2): 254-256.

7. Abou Ghayda R, Bakare T, Ohlander S, Pagani R, Niederberger C. Andrology/male infertlity subspecialty exposure during U.S based urology residency training. Fert Ster 2017 supplement;08(3):80-81.

8. Kamel M, Eltahawy EA, Warford R, Thrush CR, Noureldin YA. Simulation-based training in urology residency programmes in the USA: Results of a nationwide survey. Arab J Urol. 2018 Jul 17;16(4):446-452.

9. van Renterghem K, Ghazi A. 3D pelvic cadaver model: a novel approach to surgical training for penile implant surgery. Int J Impot Res 2019 Oct 24. doi: 10.1038/s41443-019-0211-2. [Epub ahead of print]

10. Kim SC, Fisher JG, Delman KA, Hinman JM, Srinivasan JK. Cadaver-Based Simulation Increases Resident Confidence, Initial Exposure to Fundamental Techniques, and May Augment Operative Autonomy. J Surg Educ 2016 Nov - Dec;73(6):e33-e41

11. Ahmed K, Aydin A, Dasgupta P, Khan MS, McCabe JE. A novel cadaveric simulation program in urology. J Surg Educ 2015 Jul-Aug;72(4):556-65.

12. Stefanidis D, Yonce TC, Green JM, Coker AP. Cadavers versus pigs: which are better for procedural training of surgery residents outside the OR? Surgery. 2013 Jul;154(1):34-7.

13. Kamel M, Eltahawy EA, Warford R, Thrush CR, Noureldin YA. Simulation-based training in urology residency programmes in the USA: Results of a nationwide survey. Arab J Urol. 2018 Jul 17;16(4):446-452.

14. Lentz AC, Rodríguez D, Davis LG, Apoj M, Kerfoot BP, Perito P, et al. Simulation training in penile implant surgery: Assessment of surgical confidence and knowledge with cadaveric laboratory training. Sex Med 2018 Dec;6(4):332-338.

15. Rodriguez KM, Kohn TP, Davis AB, Hakky TS. Penile implants: a look into the future. Transl Androl Urol 2017 Nov; 6 (Suppl 5): S860-S866.

16. Kovac JR. Centers of excellence for penile prosthetics are a novel concept that will likely prove difficult to implement. Transl Androl Urol 2017 Nov; 6(Suppl 5): S898S899.

17. Garber B. Inflatable penile prostheses for the treatment of erectile dysfunction. Expert Rev Med Devices. 2005 May; 2(3):341-50 
18. Wallen JJ, Madiraju SK, Wang R, Henry GD. Implementation of length expanding inflatable penile prosthesis is not sufficient to prevent postsurgical penile shortening. Asian J Androl 2019 Jan-Feb; 21(1): 98-100.

Fig 1: Cadaver stations

Fig 2a: Percentage difference in test scores from pre and post assessment

[ $\mathrm{Y}$ axis is percentage; $\mathrm{X}$ axis is question number]

Fig 2b: Difference in median confidence pre and post workshop

( $X$ axis- Question number, $Y$ axis- score range from 1 to 5 ) 
Table 1: Basic data of hands-on participants who responded both pre-workshop and postworkshop survey

\begin{tabular}{|l|l|l|}
\hline Parameters & & Overall \\
\hline $\mathrm{N}$ & & 45 \\
\hline Gender: Male & & $45(100 \%)$ \\
\hline Age (median) [range] & & $36[33-46]$ \\
\hline Implant Experience (cases) & & \\
\hline & 0 & $32(71.1 \%)$ \\
\hline & $0-10$ & $8(17.8 \%)$ \\
\hline & $>10$ & $5(11.1 \%)$ \\
\hline
\end{tabular}


Table 2: Change in number of correct answers before and after the workshop

\begin{tabular}{|c|c|c|c|}
\hline $\begin{array}{c}\text { Question } \\
\text { number }\end{array}$ & $\begin{array}{c}\text { Change in correct answers } \\
\% \text { (numbers) }\end{array}$ & P value & $\begin{array}{c}\text { Test } \\
\text { Statistics }\end{array}$ \\
\hline 1 & $62 \%$ to $82.2 \%(28$ to 37$)$ & 0.027 & 4.92 \\
\hline 2 & $24.4 \%$ to $82.2 \%(11$ to 37$)$ & $<0.0001$ & 19.531 \\
\hline 3 & $60 \%$ to $89 \%(27$ to 40$)$ & 0.007 & 6.85 \\
\hline 4 & $46.7 \%$ to $89 \%(21$ to 40$)$ & 0.001 & 12.96 \\
\hline 5 & 13.3 to $96 \%(6$ to 43$)$ & $<0.0001$ & 36.09 \\
\hline 6 & $40 \%$ to $78 \%(18$ to 36$)$ & $<0.0001$ & 13.47 \\
\hline 7 & $64.4 \%$ to $91.1 \%(29$ to 41$)$ & 0.002 & 08.64 \\
\hline 8 & $46.7 \%$ to $77.3 \%(21$ to 34$)$ & 0.003 & 08.45 \\
\hline 9 & $34.1 \%$ to $28.9 \%(15$ to 13$)$ & 0.815 NS & 0.056 \\
\hline 10 & $44.4 \%$ to $68.9 \%(20$ to 31$)$ & 0.027 & 4.76 \\
\hline 11 & $40 \%$ to $48.9 \%(18$ to 22$)$ & 0.556 NS & 0.346 \\
\hline 12 & $38 \%$ to $29.5 \%(17$ to 13$)$ & 0.690 NS & 0.180 \\
\hline 13 & $71 \%$ to $73.3 \%$ (32 to 33$)$ & NS & 1 \\
\hline 14 & $27 \%$ to $71 \%(12$ to 32$)$ & $<0.0001$ & 16.43 \\
\hline 15 & $53.3 \%$ to $86.4 \%(24$ to 38$)$ & 0.001 & 9.33 \\
\hline
\end{tabular}

(NS- Not significant) 
Table 3: Paired Samples Statistics of Level of procedural confidence assessment from 15 questions from second section of the survey

[a = after, b =before workshop]

\begin{tabular}{|c|c|c|c|c|c|c|}
\hline \multicolumn{2}{|c|}{ Question } & Mean & $\mathrm{N}$ & $\begin{array}{c}\text { Std. } \\
\text { Deviation }\end{array}$ & $\begin{array}{c}\text { Std. Error } \\
\text { Mean }\end{array}$ & $P$ value \\
\hline \multirow[t]{2}{*}{ Pair 1} & $\mathrm{a} 1$ & 4.3111 & 45 & 0.63325 & 0.09440 & \multirow[t]{2}{*}{$<.001$} \\
\hline & b1 & 2.4667 & 45 & 1.23583 & 0.18423 & \\
\hline \multirow[t]{2}{*}{ Pair 2} & $\mathrm{a} 2$ & 4.4000 & 45 & 0.65366 & 0.09744 & \multirow[t]{2}{*}{$<.001$} \\
\hline & b2 & 2.9556 & 45 & 1.33068 & 0.19837 & \\
\hline \multirow[t]{2}{*}{ Pair 3} & a3 & 4.2667 & 45 & 0.78044 & 0.11634 & \multirow[t]{2}{*}{$<.001$} \\
\hline & b3 & 2.5778 & 45 & 1.35661 & 0.20223 & \\
\hline \multirow[t]{2}{*}{ Pair 4} & a4 & 3.5111 & 45 & 1.16037 & 0.17298 & \multirow[t]{2}{*}{$<.001$} \\
\hline & b4 & 1.8889 & 45 & 1.13262 & 0.16884 & \\
\hline \multirow[t]{2}{*}{ Pair 5} & a5 & 4.2889 & 45 & 0.92004 & 0.13715 & \multirow[t]{2}{*}{$<.001$} \\
\hline & b5 & 2.8444 & 45 & 1.34765 & 0.20090 & \\
\hline \multirow[t]{2}{*}{ Pair 6} & $\mathrm{a} 6$ & 4.7556 & 45 & 0.43461 & 0.06479 & \multirow[t]{2}{*}{$<.001$} \\
\hline & b6 & 3.5111 & 45 & 1.30771 & 0.19494 & \\
\hline \multirow[t]{2}{*}{ Pair 7} & a7 & 4.3556 & 45 & 0.67942 & 0.10128 & \multirow[t]{2}{*}{$<.001$} \\
\hline & b7 & 2.6889 & 45 & 1.44320 & 0.21514 & \\
\hline \multirow[t]{2}{*}{ Pair 8} & a8 & 4.4222 & 45 & 0.69048 & 0.10293 & \multirow[t]{2}{*}{$<.001$} \\
\hline & b8 & 2.3778 & 45 & 1.24843 & 0.18611 & \\
\hline \multirow[t]{2}{*}{ Pair 9} & a9 & 4.1111 & 45 & 0.80403 & 0.11986 & \multirow[t]{2}{*}{$<.001$} \\
\hline & b9 & 2.6000 & 45 & 1.32116 & 0.19695 & \\
\hline \multirow{2}{*}{$\begin{array}{l}\text { Pair } \\
10\end{array}$} & a10 & 4.0667 & 45 & 0.83666 & 0.12472 & \multirow[t]{2}{*}{$<.001$} \\
\hline & b10 & 2.2667 & 45 & 1.42063 & 0.21177 & \\
\hline Pair & a11 & 4.1333 & 45 & 0.75679 & 0.11282 & \multirow[t]{2}{*}{$<.001$} \\
\hline 11 & b11 & 2.1111 & 45 & 1.21023 & 0.18041 & \\
\hline Pair & a12 & 4.4444 & 45 & 0.65905 & 0.09824 & \multirow[t]{2}{*}{$<.001$} \\
\hline 12 & b12 & 3.1111 & 45 & 1.30074 & 0.19390 & \\
\hline Pair & a13 & 3.8000 & 45 & 0.94388 & 0.14071 & \multirow[t]{2}{*}{$<.001$} \\
\hline 13 & b13 & 2.3111 & 45 & 1.31118 & 0.19546 & \\
\hline Pair & a14 & 4.2889 & 45 & 0.81526 & 0.12153 & \multirow[t]{2}{*}{$<.001$} \\
\hline 14 & b14 & 2.4889 & 45 & 1.29021 & 0.19233 & \\
\hline Pair & a15 & 4.2667 & 45 & 0.83666 & 0.12472 & \multirow[t]{2}{*}{$<.001$} \\
\hline 15 & b15 & 2.1333 & 45 & 1.30732 & 0.19488 & \\
\hline
\end{tabular}


Table 4: Confidence questions using Median

\begin{tabular}{|l|l|l|l|}
\hline Questions & $\begin{array}{l}\text { Pre assessment (45) } \\
\text { Median (IQR) }\end{array}$ & $\begin{array}{l}\text { Post assessment (45) } \\
\text { Median (IQR) }\end{array}$ & P value \\
\hline 1 & $3(1,3)$ & $4(4,5)$ & $<.001$ \\
\hline 2 & $3(2,4)$ & $4(4,5)$ & $<.001$ \\
\hline 3 & $3(1,4)$ & $4(4,5)$ & $<.001$ \\
\hline 4 & $1(1,3)$ & $3(3,4)$ & $<.001$ \\
\hline 5 & $3(1,4)$ & $4(4,5)$ & $<.001$ \\
\hline 6 & $4(3,4.5)$ & $4(4,5)$ & $<.001$ \\
\hline 7 & $3(1,4)$ & $4(4,5)$ & $<.001$ \\
\hline 8 & $2(1,3)$ & $4(4,5)$ & $<.001$ \\
\hline 9 & $3(1,4)$ & $4(4,5)$ & $<.001$ \\
\hline 10 & $2(1,3)$ & $3(4,5)$ & $<.001$ \\
\hline 11 & $2(1,3)$ & $4(4,5)$ & $<.001$ \\
\hline 12 & $3(2,4)$ & $4(4,5)$ & $<.001$ \\
\hline 13 & $2(1,3)$ & $4(3,5)$ & $<.001$ \\
\hline 14 & $2(1,3.5)$ & $4(4,5)$ & $<.001$ \\
\hline 15 & $2(1,3)$ & $4(4,5)$ & $<.001$ \\
\hline
\end{tabular}

IQR interquartile range 


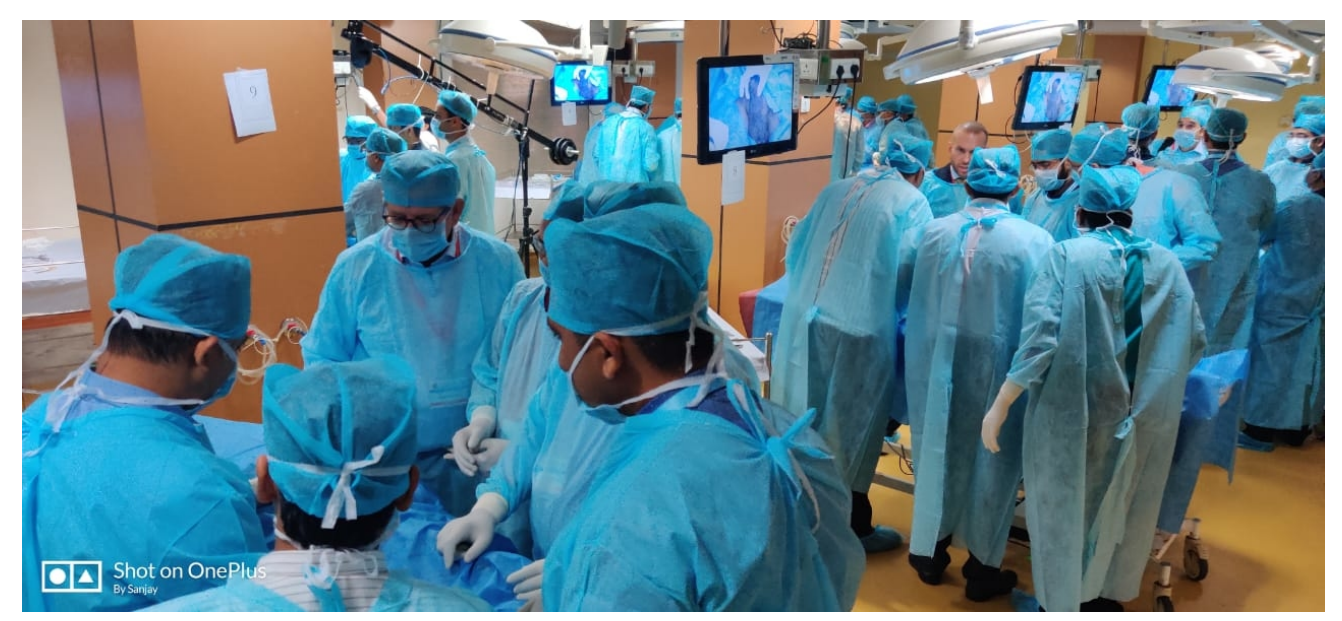

Fig 1: Cadaver stations

$451 \times 205 \mathrm{~mm}(72 \times 72$ DPI $)$ 
Fig 2a: Percentage difference in test scores from pre and post assessment

[ $\mathrm{Y}$ axis is percentage; $\mathrm{X}$ axis is question number]

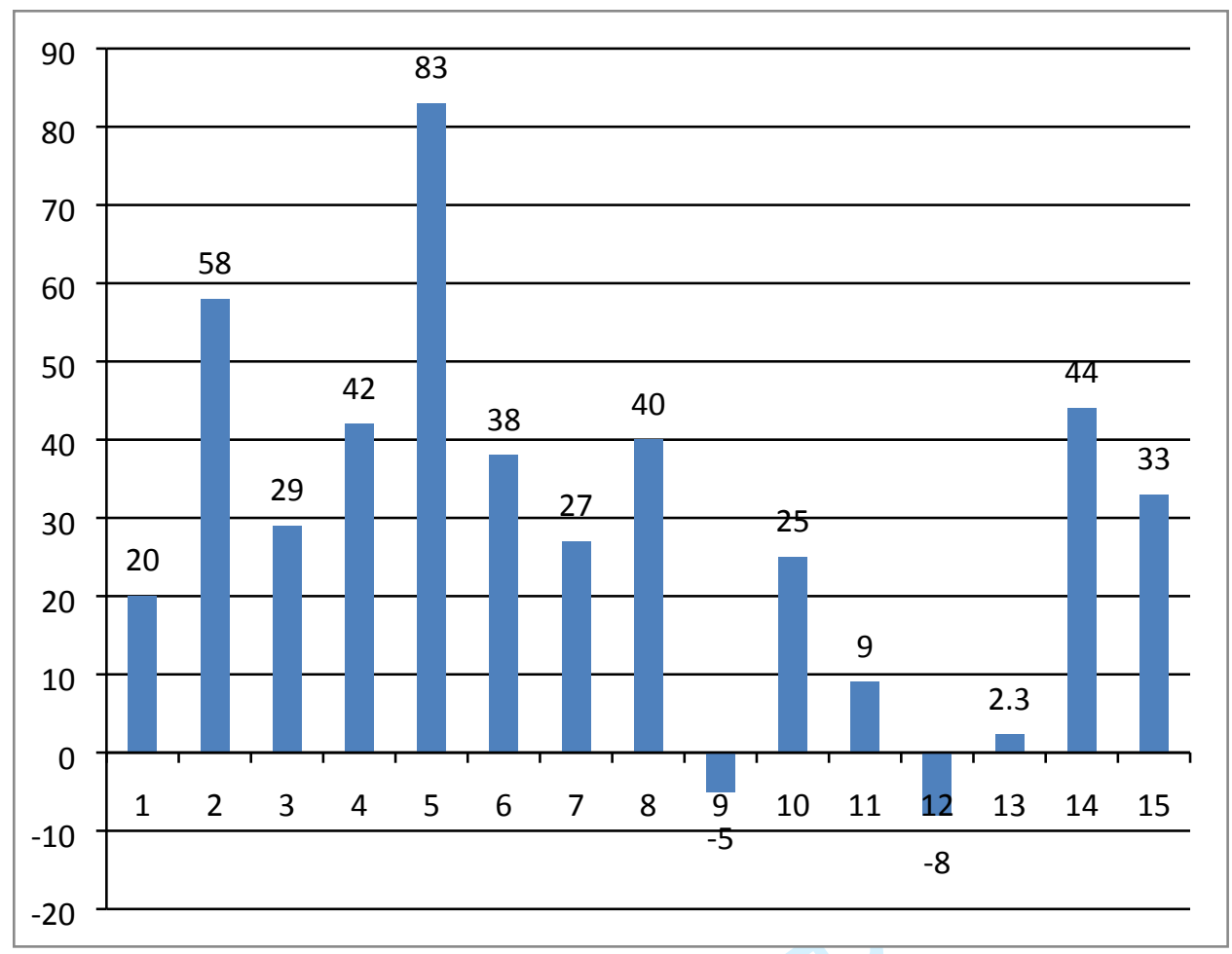


Fig 2b: Difference in median confidence pre and post workshop

( $X$ axis- Question number, $Y$ axis- score range from 1 to 5 )

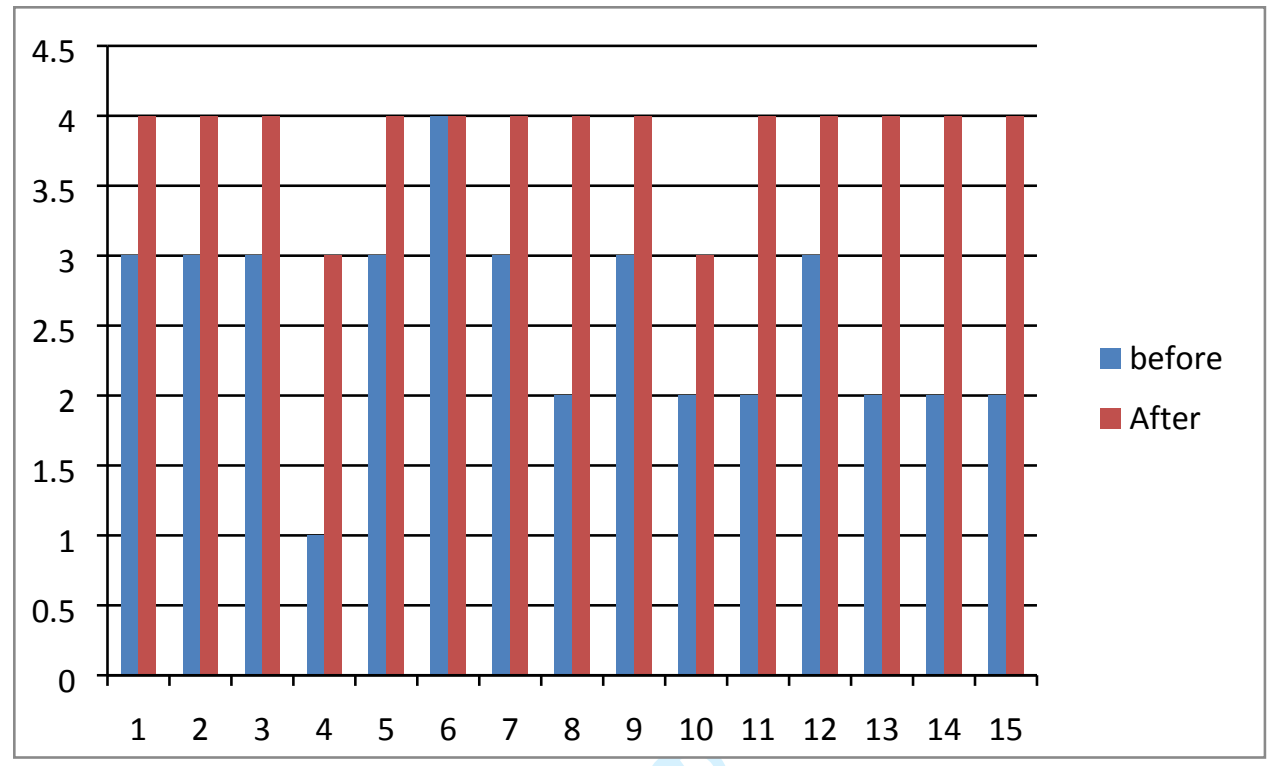




\section{$<$ H1 $>$ Appendix}

\section{$<$ H2 $>$ Survey}

1) The 3 most commonly used surgical approaches for penile prosthesis implantation are:
a. ventral penile, infrapubic, inguinoscrotal
b. sub coronal, inguinoscrotal, penoscrotal
c. ventral penile, infrapubic, penoscrotal
d. inguinoscrotal, infrapubic, penoscrotal
e. subcoronal, infrapubic, penoscrotal

Answer: e

2) Before scheduling a patient for penile prosthesis surgery, the patient must:
a. have tried and failed oral phosphodiesterase type 5 inhibitors, vacuum erection device therapy, and intracavernosal injection therapy
b. undergo weight loss to achieve a body mass index $<35$
c. achieve a hemoglobin $\mathrm{A} 1 \mathrm{C}<7.0$
d. be educated in first- and second-line therapies
e. undergo correction of a preexisting Peyronie's defect

Answer: d

3) Which of the following bacteria retardant coatings are currently being used in modern penile implants?
a. minocycline, rifampin, polyvinylpyrrolidone
b. gentamicin, vancomycin, polyvinylpyrrolidone
c. gentamicin, vancomycin, rifampin
d. gentamicin, rifampin, Betadine
e. minocycline, vancomycin, Betadine

Answer: a

4) The currently preferred surgical site skin prep is:
a. Triclosan
b. Povidone-iodine
c. Chlorhexidine
d. Chlorhexidine-alcohol
e. Povidone-iodine-alcohol

Answer: d 
5) Which of the following is associated with a higher risk of implant infection?
a. Smoking status
b. Human immunodeficiency virus status
c. Obesity
d. Prior renal transplantation
e. Intermittent catheterization

Answer: a

6) During revision surgery for mechanical malfunction, you must always perform:
a. Removal of all components, including the reservoir
b. Copious washout of the implant spaces
c. Change gown, gloves, and drapes during the case
d. Continue on oral antibiotics for 1 week
e. Use a "No-touch" technique

Answer: $b$

7) Which of the following is not an accepted intraoperative adjunctive straightening maneuver for patients with both erectile dysfunction and Peyronie's disease?
a. Mechanical modeling
b. Plication
c. Corporoplasty
d. Grafting
e. Collagenase

Answer: e

8) Which of the following is true with regard to a proximal corporal perforation?
a. A Gore-Tex windsock is needed in every case
b. It only happens to inexperienced implanters
c. Is best repaired through a perineal incision
d. Perforation with a narrow dilator does not always require formal repair
e. A rear-tip sling is secured with an absorbable suture

Answer: d

9) The feature that differentiates the AMS 700 LGX prosthesis (Boston Scientific, Marlborough, MA, USA) from others is:

a. penile girth expansion 

b. penile length expansion
c. it has 2 pieces
d. it is preconnected
e. it is prefilled

Answer: $b$

10) Clinical signs of a cylinder crossover include all of the following except:
a. Unequal corporal measurements
b. Difficulty inserting the second cylinder
c. Asymmetrical appearance of the 2 corpora
d. Proximal measurements greater than distal measurements
e. A lopsided erection

Answer: d

11) During dilation of the corpora, blood is noted at the urethral meatus and irrigation through the corporotomy confirms a urethral injury. The best management is:
a. Abort implantation and place a urethral catheter
b. Continue implantation and place a urethral catheter
c. Abort implantation and place a suprapubic catheter
d. Continue implantation and place a suprapubic catheter
e. Repair the urethra and continue with implantation

Answer: a

12) 6 months after insertion of a 3-piece implant, the patient complains of scrotal pain with adherence of his scrotal skin to the pump. The most likely cause of the symptoms and physical findings is:
a. allergy to silicone
b. mechanical irritation from too much pumping
c. oversized cylinders
d. infection with gram positive organisms
e. infection with gram negative organisms

Answer: d

13) Cylinder crossover is corrected by:
a. Removing both cylinders and terminate the procedure
b. Leaving 1 cylinder on the side opposite the crossover
c. Placing a dilator on the side that did not crossover and re-dilate the contralateral side
d. Repairing the septal perforation 
e. Performing corporoscopy with a flexible cystoscope to assess the damage

Answer: c

14) Techniques to reduce the risk of bladder or bowel injury include all the following except:
a. Submuscular reservoir location
b. Placing the bed in Trendelenburg position
c. Using the smallest reservoir possible
d. Foley catheter decompression
e. A counterincision to place the reservoir under direct vision

Answer: c

15) A 3-piece inflatable prosthesis is contraindicated in the following patients:
a. Status postorthotopic neobladder
b. Previous history of Fournier's gangrene
c. Spinal cord injury
d. Severe corporal fibrosis
e. Compromised manual dexterity

Answer: e

\section{$<$ H2>Section 2: Self-Rated Procedural Confidence}

Please use the scale below to rate your confidence in the following aspects of penile prosthesis surgery:

$1=$ not at all confident

$2=$ minimally confident

$3=$ average confidence

$4=$ above average confidence

$5=$ very confident

1) I can adequately assess patients as candidates for penile implant surgery and appropriately counsel them on risks, benefits, and alternatives to penile implant surgery.

2) I am familiar with evidence-based techniques to minimize infection and can select the correct preoperative antibiotics and surgical skin prep.

3) I can fully explain the advantages and disadvantages of infrapubic, penoscrotal, and subcoronal approach.

4) I can describe the differences between implant models including; CX, LGX, CXR, Ambicor, Spectra (Boston Scientific, Marlborough, MA, USA), Titan, Narrow Base, Genesis (Coloplast, Minneapolis, MN, USA). 
5) I can identify medical and surgical comorbidities that increase the risk of implant-related complications.

6) I can efficiently identify and expose the corporal bodies.

7) I am comfortable with dilating and sizing the corporal bodies as well as techniques to identify and prevent crossover.

8) I understand the basic principles of selecting the correct cylinder length and rear-tip extender.

9) I am comfortable creating a reservoir space in the traditional space of Retzius or in a submuscular location anterior to the transversalis fascia.

10) I can perform placement of the cylinders into the proximal and distal corpora and I am comfortable with trouble-shooting techniques such as an inflation test with a surrogate reservoir.

11) I can recognize and treat proximal corporal perforation.

12) I can recognize and treat a urethral injury.

13) I understand how and when to use adjunct maneuvers for Peyronie's disease.

14) I am able to correctly place the pump in a dependent portion of the scrotum.

15) I understand and can perform maneuvers to decrease hematoma formation including scrotal drain placement and mummy-wrap techniques. 